\title{
Scenario Simulation of Ecosystem Services Value Changes and Its Implication for Sustainability Development Goals
}

\author{
Shishay kiros weldegebriel ${ }^{1 *} \quad$ Ranavijai Singh $^{1} \quad$ Kumelachew Yeshitela $^{2}$ \\ 1 Ethiopian Civil Service University, Addis Ababa, Ethiopia \\ 2 Ethiopian Institute of Architecture, Building Construction and City Development, Addis Ababa University, \\ Addis Ababa, Ethiopia
}

\begin{abstract}
This study quantified the effect of future land use/ land cover changes on ecosystem service values under different scenarios in Mekelle city region for the year 2030. The study utilized land use/land cover changes data of the year 2019 and predicted LULC changes for the year 2030. Identification of the driving forces, was the most important step in predicting the future LULC and was performed using the cellular automata models in CLUDMondo which is a future land use simulation model by coupling human and the natural effects. Scenarios were made under business as usual, implementation of PES schemes and spatial planning. In business-as-usual scenario, it was observed that ecosystem services value will decline by 2030 from the base year of 2019, whereas under spatial planning scenario, the ecosystem service value will increase by $5.2 \%$. Such results can serve as useful information in policy formulation in developing land use options, which help enhance ecosystem service value in future. Therefore, special attention should be given to the rehabilitation of ecosystems, the protection of the remaining natural vegetation and water bodies. Overall, these results provide useful inputs to planners to adopt eco-friendly policies to achieve sustainable development goals.
\end{abstract}

Keywords: Scenario, ecosystem service, value, land use/land change, sustainable development goals

DOI: $10.7176 / \mathrm{JRDM} / 75-04$

Publication date:May $31^{\text {st }} 2021$

\section{Introduction}

Dynamic models of ecosystem services and scenario analysis are being increasingly used to support decision making in land use planning(Ardavan Zarandiana, 2017).Projection of futures landscape changes requires understanding and integration of past landscape trends, current land change processes and feedbacks, and the incorporation of plausible scenarios. Obviously, monitoring and modelling of landscape dynamics strongly depends on the scale and objectives of the planned applications(Houet, Verburg, \& Loveland, 2010).Modelling ecosystem services (ES) is an essential tool for the development of strategies that will ensure their future supply, provision and quantification(Olosutean, 2015).

The prediction and simulation of future land use change can improve the foresight of land use planning, which is of great implication to regional sustainable development.(Hu et al., 2020).The relationship between ES and land-use changes highlights the importance of ES in guiding land-use planning and ecosystem management strategies to promote sustainability( $\mathrm{Z}$. Li, Cheng, \& Han, 2020).The scenario analysis of ecosystem services can provide a scientific basis for sustainable ecosystem management.(Fu et al., 2018).Monitoring the impact of current Land Use/Land Cover (LULC) management practices

on future Ecosystem Services (ESs) provisioning has been emphasized because of the effect of such practices on ecological sustainability(Yirsaw, Wu, Shi, Temesgen, \& Bekele, 2017).

The value of ecosystem services is now widely acknowledged for their optimistic role in economic, environmental, social well-being and in achieving the three pillars of sustainable development(Pandeya et al., 2016). Mekelle's Urbanisation is an inevitable trend, and the economic development that accompanies urbanisation can have major negative implications and impacts for ecosystem services. However, Mekelle city can play a crucial part of the solution if nature and biodiversity are considered as essential parts of the city urban planning and taken into account through formal urban planning, management and legislation processes. Mekelle city tend to expand, in areas important for biodiversity such watersheds. Biodiversity and ecosystem services both within cities and beyond their boundaries are important for the urban population as they contribute with food and drinking water, regulate temperature, absorb pollution, reduce vulnerabilities and disaster risks, and provide liveable places and recreational opportunities that contribute to human well-being.

Unplanned urbanization is likely to result in significant ecosystem loss when natural habitats are fragmented or replaced through construction of infrastructure and through city extensions. Despite its importance, this ecosystem services in the study area are poorly understood, scarcely monitored at city region level, and as a result there is rapid degradation and depletion. There is greater uncertainty about future ecosystem services supply in Mekelle city region. Monitoring the negative consequences of LULC while sustaining the supply of essential ecosystem services is vital. Therefore, this study intended to estimate the land use changes over the time and predict the future ecosystem services values of Mekelle city region. Therefore, the objective of this 
study were to: simulate the future land use/land cover changes and ecosystem service values and its implications in achieving sustainable development goals.

\section{Material and methods}

\subsection{Study area}

Mekelle city and its hinterlands which are significant in terms of watershed ecosystem services for the metropolitan Mekelle city are named as city region (figure 1). The landscape is located within Tigray region, northern part of Ethiopia found in west 39.362942, East 39.687048, North 13.680920 and south 13.342621 about $760.61 \mathrm{~km}$ north of Addis Ababa and the area covered in this investigation is 897.12 square kilometers $(89,712$ hectares). The study area is characterized by varied topographic conditions. The elevation ranges from 1700 meters in the Geba river to 2685 meters Ellala and Gebat river catchment. The core city of the study area Mekelle city is $2062 \mathrm{~m}$ above sea level. The climate is predominantly semi-arid with irregular rainfall and frequent drought periods. The mean annual rainfall of the is estimated to be less than $532 \mathrm{~mm}$ (Veen, 2014).Climatically, the area has a semi-arid climate with little variation and it is knowns by its environmental vulnerability (Abreha, 2014). The agro-climatic zone of the study area is mild climatic condition. The monthly mean minimum temperature is $15^{\circ} \mathrm{C}$ and maximum monthly temperature may go as high as $28^{\circ} \mathrm{C}$. The study area population is 556127 (TCSA, 2019).

Figure 1: Location Map of Mekelle city region

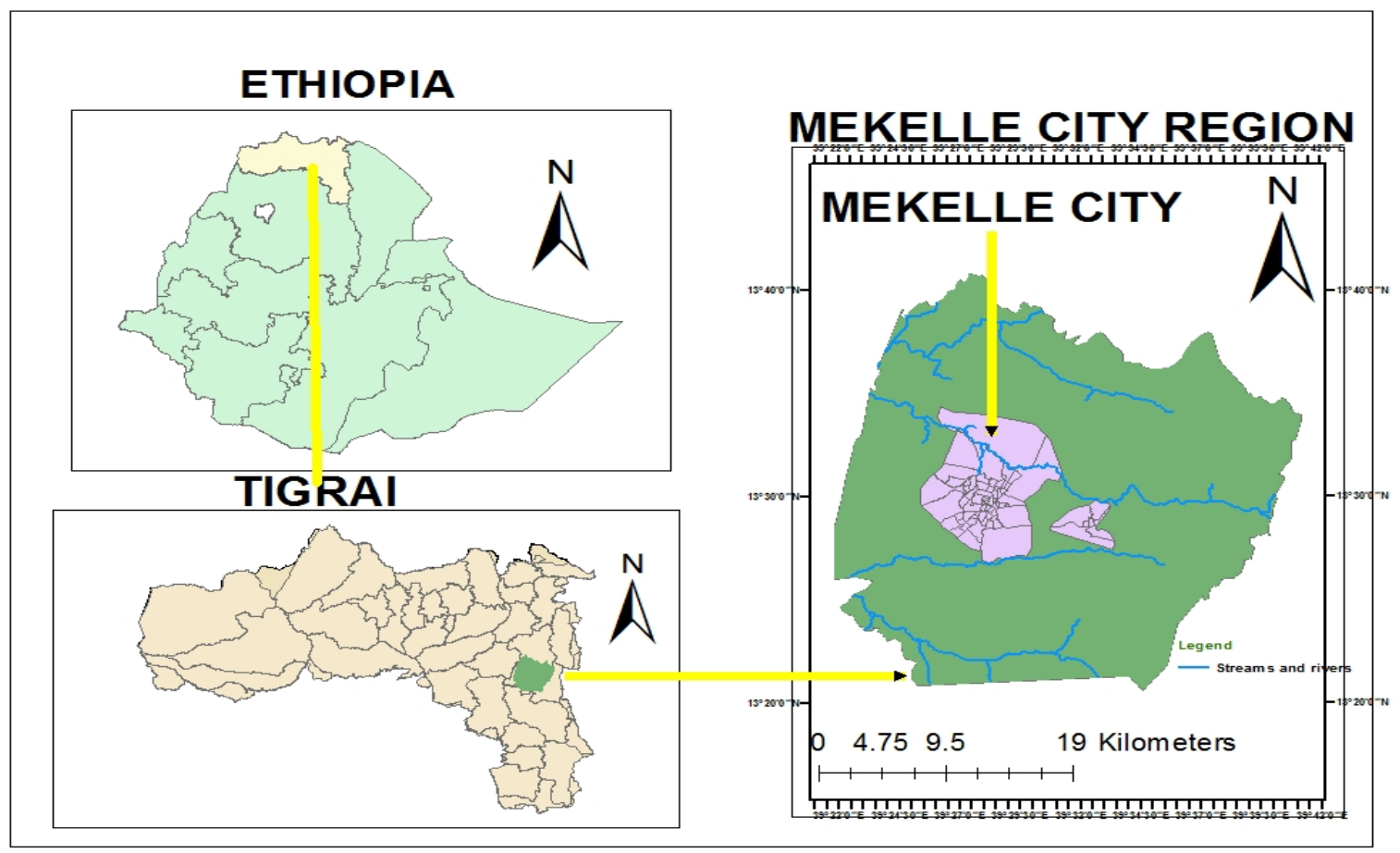

Source: Author, 2019

\subsection{Data sources and processes}

\subsubsection{For the scenario simulation}

The transition probability of change was represented by Markov chain analysis. The existence of a dynamic system represents the probability of a land-use type that will change from one class to another and/or stay in the same, depending on the class at the initial time. In this analysis, the transition probability was used to estimate the probability of land use dynamics within a specified period. Driver-based simulating land dynamics was made in Mekelle city region. To model future, land-use changes additional spatial explicit datasets were created, which represent both the anthropogonic and biophysical drivers. This study used past land use/land cover changes observed data obtained from the Landsat series for the year 2019 and the simulated LULC dataset that was created using CLUMondo. This CLUMondo simulation tool which is available as a free and open-source model. CLUMondo simulates changes in land systems in response to an exogenous demand, land system, and a series of biophysical and anthropogonic variables.CLUMondo is a dynamic, spatially explicit land use and land cover change model(Van Vliet \& Verburg, 2018).In addition to this, Map Comparison Kit (MCK) tool was used that includes numerous algorithms for comparing raster maps, which are particularly useful for land use dynamics simulation models. 
Biophysical drivers such as mean monthly temperature and mean annual rainfall was prepared using IDW 3D analysis in Arc GIS, and anthropogonic drivers such as population density i.e Population density per pixel at 100-meter resolution was used which is found at (https://energydata.info/dataset/ethiopia-population-density2015 by (Tatem, 2015)) drivers' data were collected and organized for those corresponding years for analysis from various sources. The elevation and slope obtained from digital terrain model (DEM, $30 \mathrm{~m}$ ) from USGS (https://earthexplorer.usgs.gov/) SRTM1 Arc-second global. The slope was extracted using spatial analyst tool and elevation using create tin (3D analyst) in Arc GIS. To prepare distance to roads Euclidean tool was applied.

To analyze and assess them in a model set-up, all drivers were converted to raster format. The average values of temperature and precipitation from was converted to raster data using statistical tools in Arcgis 10.5 software, the raster spatial resolution was $30 \mathrm{~m}$ accordant with the remote sensing data. All raster data were converted to the same projection coordinate system UTM WGS1984_UTM_Zone_37N and a spatial resolution of $30 \mathrm{~m}$ using ArcGIS. Thereby to avoid the modifiable aerial unit problem and for the sake of unbiased analysis, data were resampled at a uniform spatial level and were aligned in the same format, having the same projection and resolution parameters as those of the LULC raster maps.

\subsubsection{For Ecosystem services valuation}

LULC data for the year 2019 is the key data used for ecosystem service valuations. Then, the values for ecosystem services per unit area by biome and was multiplied by the total area of each biome and finally summed over all ecosystem services and biomes. The classified images were compared with the representative biomes i.e LULC types in order to obtain their corresponding ESV coefficients identified.

Table 1: LULC types with their area in hectares for 2019 and biome counterparts with the corresponding value coefficients ( US $\$$ ha $^{-1}$ year $^{-1}$ ) modified conservative value coefficients mainly based on the TEEB database by (Kindu, Schneider, Teketay, \& Knoke, 2015).

\begin{tabular}{|l|l|l|l|}
\hline S. N & Class name & Equivalent biome & $($ US \$ ha \\
\hline 1 & Built-up area & year & $\mathbf{- 1}$ \\
\hline 2 & Natural forest & Settlement & 0 \\
\hline 3 & Plantation forest & Tropical forest & 986.69 \\
\hline 4 & Water body & Tropical forest & 986.69 \\
\hline 5 & Cultivated land & Lakes/rivers fresh water & 8103.5 \\
\hline 6 & Grass land & Cropland & 225.56 \\
\hline 7 & Bushes and Shrubs & Grass/rangelands & 293.25 \\
\hline 8 & River side vegetation & Wood land & 986.69 \\
\hline 9 & Bare land & Wood land & 986.69 \\
\hline
\end{tabular}

The study employed modified conservative value coefficients developed by (Kindu et al., 2015) in order to contextualize it to Ethiopian and Mekelle city region context. Based on the model quantifications of ESVs changes induced by LULC using a conservative coefficient which is a benefit transfer approach was applied. This value coefficient is assumed to be suitable for Mekelle city region. Following the ESVs methodology used by (Costanza et al., 1997; Kindu et al., 2015; J. Li, Chen, Zhang, \& Pan, 2019; Tolessa, Gessese, Tolera, \& Kidane, 2018; Yang, 2008).To estimate ESV the following equation is used.

$$
\mathrm{ESV}=\Sigma\left(\mathrm{A}_{\mathrm{k}} \times \mathrm{VC}_{\mathrm{k}}\right)
$$

Where ESV is the total estimated ecosystem service value, Ak is the area in (ha) and VCk the corresponding value coefficient (US\$ ha-1 $\mathrm{yr}-1$ ) for each LULC category $\mathrm{k}$. The total value of ecosystem services for the year 2019 and 2030 was obtained by; the area of each LULC type in hectare was multiplied by its corresponding value coefficients to calculate the total ecosystem service value for a particular LULC type. The values for the LULC types in each reference year were summed to estimate total ESV of the landscape for each reference year. This study estimated future ESV using the predicted map of the year 2030 LULC charges under different scenarios. 


\subsection{Data analysis}

Figure 2: Iteration procedure applied for scenario generation

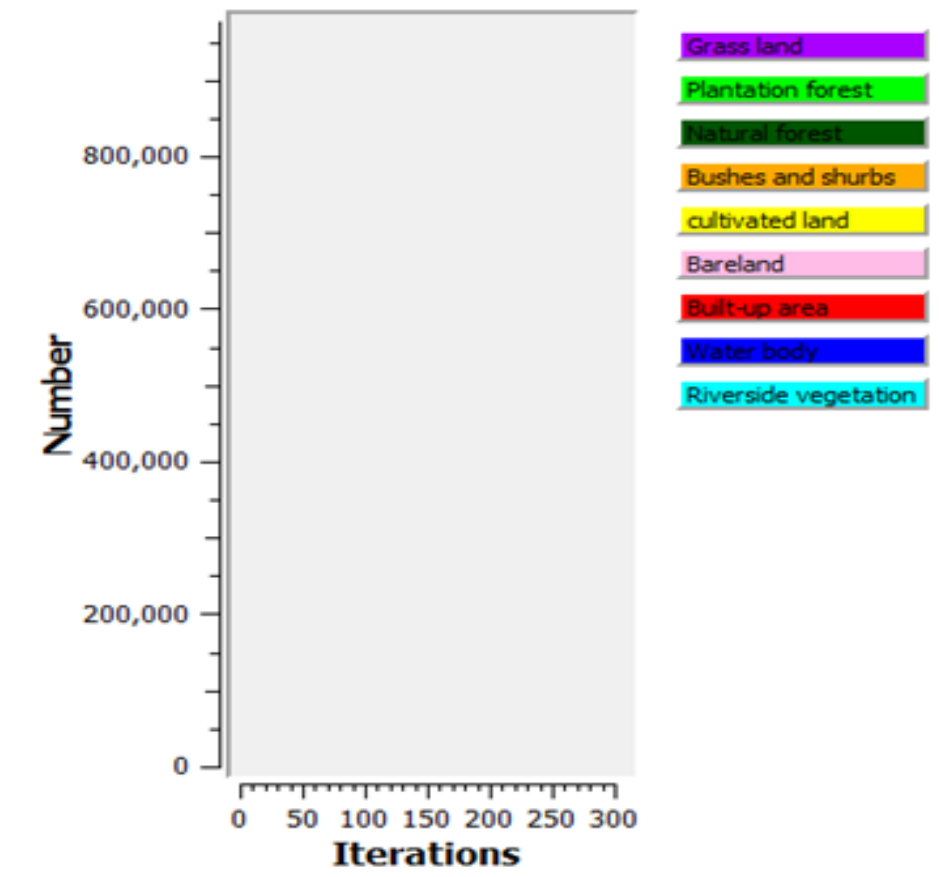

Within each yearly time step, land systems were allocated in an iterative procedure in which land systems are allocated according to the transition potential at time $(\mathrm{t})$ and location (i) for each land system (LS), and the demands for goods and services for that specific year. The CLUMondo involves four broad inputs, namely land demand, location characteristics, spatial policies and restriction and land use conversion setting(Verburg, Vliet, Malek, \& Ornetsmuller, 2015).

\section{Estimating land use demand}

Mekelle city region has been experiencing huge land use transformation in the last five decades and the change. The future land use dynamics scenarios for the year 2030 were simulated the future land uses that would meet the different level of conservation objectives of ecosystem service values. The land use demands were calculated outside the CLUMondo model using external model, which calculates the allocation of land use dynamics depending on the study area and the scenario. The climate, including mean monthly temperature and annual rainfall is assumed to maintain the current state.

Scenario A- business as usual (BAU): this scenario assumes land use dynamics of the past 2019 will also continue, in which the LUCC of 2019 was used to project 2030 land cover without any planning restrictions and is assumed that land use dynamics will continue until 2030. The analysis of this study on land use dynamics and its effects on ecosystem service values of the past confirm a decline in ecosystem service value. Henceforward, there is likely deterioration in ecosystem service value, due urbanization and generally the built-up area is projected to increase significantly in 2030. In contrast, plantation forest, bushes and shrubs, natural forest, water bodies, grass land, river side vegetation, bare land and cultivated land are projected to decrease sharply. If this scenario persists, it will have a severe impact on ecosystem service values.

Scenario B- implementation of PES schemes: the current trend of LULC changes would be halted with a hypothetical WTP and implementation of PES schemes. Under the PES scenario, LULC changes are more moderate and slower, and plantation forest, bushes and shrubs, water body, grass land, river side vegetation will increase significantly from. And it is assumed built-up areas will increase and cultivated land and bare lands will decrease. This scenario sets balanced emphasis on enhancing the value of ecosystem services and urbanization and built-up area expansion through regional spatial planning. This scenario assumed increase of population and economic development. At the same time, the demands for built-up areas, including urban and rural residential land, construction land, and transport facility areas, would expand rapidly. To meet the growing population's demand for food, cultivated land will show less of a decline than the BAU scenario.

Scenario C -Spatial planning: This scenario puts balanced emphasis on continuing urbanization and enhancing ecosystem service values through integrated land uses plans. This scenario assumes regional spatial planning will be implemented and ecosystem service values will increase. This scenario aims to increase overall ESVs from the current situation by 2030 . For instance, currently steepy slopes that were under cultivation could be used for plantation forest, and degraded river side vegetation by managing the land properly and made intensive 
plantations. In addition, this scenario anticipates effective protection of remaining ecosystem in all existing and proposed protected areas. This scenario assumes that a more regulated urban development will be implemented. The scenario can be viewed as a harmonious development scenario which is characterized by condensed and slower built-up area and urbanization expansion in which the environment will be considered. This scenario gives priority to protection of ecosystem restricted from being converted to other land uses. Furthermore, the area of built-up would show a slight decreases and natural forest, plantation forest, water bodies and river side vegetation would increase more than other scenarios. This scenario will reduce the speed of the negative effects of urban expansion on ecosystem service values.

\section{Determining location characteristics}

The location factors were determined by assuming that the locations are devoted to land use type with the highest suitability as the location characteristics, such DEM, distance to roads, mean annual rainfall, mean monthly temperature, population density and slope which are directly related to a specific location. The significant drivers recognized for each land use category were used as input for projecting in terms of their level of significance on the respective land use class. According to their correlation coefficient, the set of drivers were inserted in the regression equation as the independent $\mathrm{X}$ variables to estimate the predicted $\mathrm{Y}$ (land use/dependent variable). For 2030, the base year (T1) of prediction was 2019. Hereafter regression analysis was carried out on the driver's datasets. Multinomial Logistic regression predicts the probability of events under the comprehensive influence of multiple factors. The target variable of this study is the LULC changes in 2019 which is a binary variable. The dependent variable represents the presence or absence of LULC.

The relationship between futuristic land use /land cover changes was established through multinomial logistic regression for each LULC type and a set of defined driving. The study used this model to calculate the probability with the biophysical and anthropogonic location characteristics as follows:

$$
\log \left[\frac{P_{i}}{1-P_{i}}\right]=\beta_{0}+\beta_{1} X_{1, i}+\beta_{2} X_{2, i} \ldots \ldots+\beta_{n} X_{n, i}
$$

Where, $\mathrm{Pi}$ is the probability of a grid cell $\mathrm{i}$ for the occurrence of the land use type. X's are the location factors. The coefficients $(\beta)$ are regression coefficients and were estimated through multinomial logistic regression using the actual land use changes as dependent variable. The model was to determine the observed relationships between a binary dependent LULC changes classes and several independent continuous variables. For the dependent represents LULC changes results, Y has a binary value of 1 and 0.

Table 2: List of variables included in the model

\begin{tabular}{|l|l|l|}
\hline Variable & Definition & Name of variable \\
\hline Dependent & & \\
\hline Y & 0 no LULC changes ,1 LULC changes & Dichotomous \\
\hline Independent & & \\
\hline X1 & Population density & continuous \\
\hline X2 & DEM & continuous \\
\hline X3 & Distance to roads & continuous \\
\hline X4 & Slope & continuous \\
\hline X5 & Mean annual rainfall & continuous \\
\hline X6 & Mean monthly temperature & continuous \\
\hline
\end{tabular}

The independent variables data were named as population density (POP), DEM(DEM), distance to roads (DIS), slope (SLO), mean annual rainfall (RAI) and mean monthly temperature (Temp). Those factors influence the distribution of human dominated land cover. Hence, to investigate the association between a categorical dependent LULC change variable and a set of independent driver's multinomial logistic regression model was used. The dependent variable has only two values of 0 and 1 .

\section{Land use conversion rate}

The CLUMondo modelling tool has many parameters and these wee specified prior to running the simulation. The parameter setting is dependent on the assumptions made for a specific scenario. The conversion resistance is the settings specific to a particular land use type, which determines the temporal dynamics of the simulation. It tells the reversibility of land use dynamics. The parameter was estimated from 0 which is easy conversion and to 1 i.e. irreversible change. For simulation, the high resistance set value of 0.7 to 1.0 was assigned to forest cover, water bodies and built-up area because it is not desirable to convert these land cover type. The conversion matrix indicates the land use conversions that were allowed between the land uses. A value of 1 indicates that the conversion is allowed, and 0 indicates no conversion. The future land use dynamics was predicted as per the procedural requirements of CLUMondo, which basically requires information on locational characteristics, spatial policies and restrictions, land use conversion rates. Some of locational characteristics, such as rainfall and 
temperature may vary over time and policy may change in future but this is hard to undertake for distant future. The urbanization is concerned it is likely that there will be rapid change. Weight of neighborhood was set for different land use types ranging from 0-1. Finally, the ecosystem service values of future were calculated based on the predicted areal coverage of each land use type by the year 2030 .

Major steps used for predictions

The study used the following methodology to predict LULC changes.

1. Temporal analysis

The land use/land cover changes were analysed using ERDAS imagine software. The CLUMondo software was used to simulate the spatial-temporal evolution of complex phenomena based on the transformation rules. Then the Markov model calculated between two periods the amount of change using the initial state and the transition probability and used for prediction of land use land cover change. Based on the initial(T1) and base year(T0), future land use was simulated for 2030(T2) which is aligned with the 2030 agenda for Sustainable development goals.

Figure 3: Land use land cover classified image of the base line year 2019

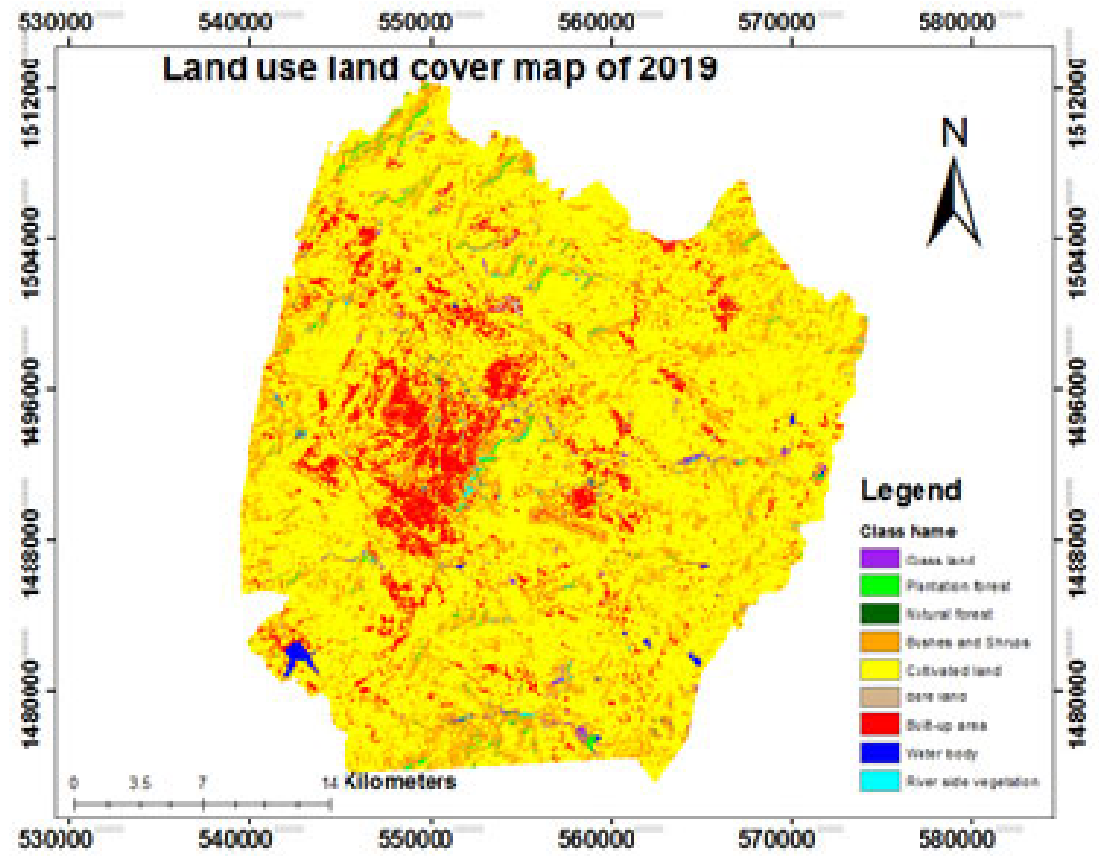

\section{Preparation of database}

Datasets for land use/land cover changes and drivers were organized in a similar format convenient of simulation. 

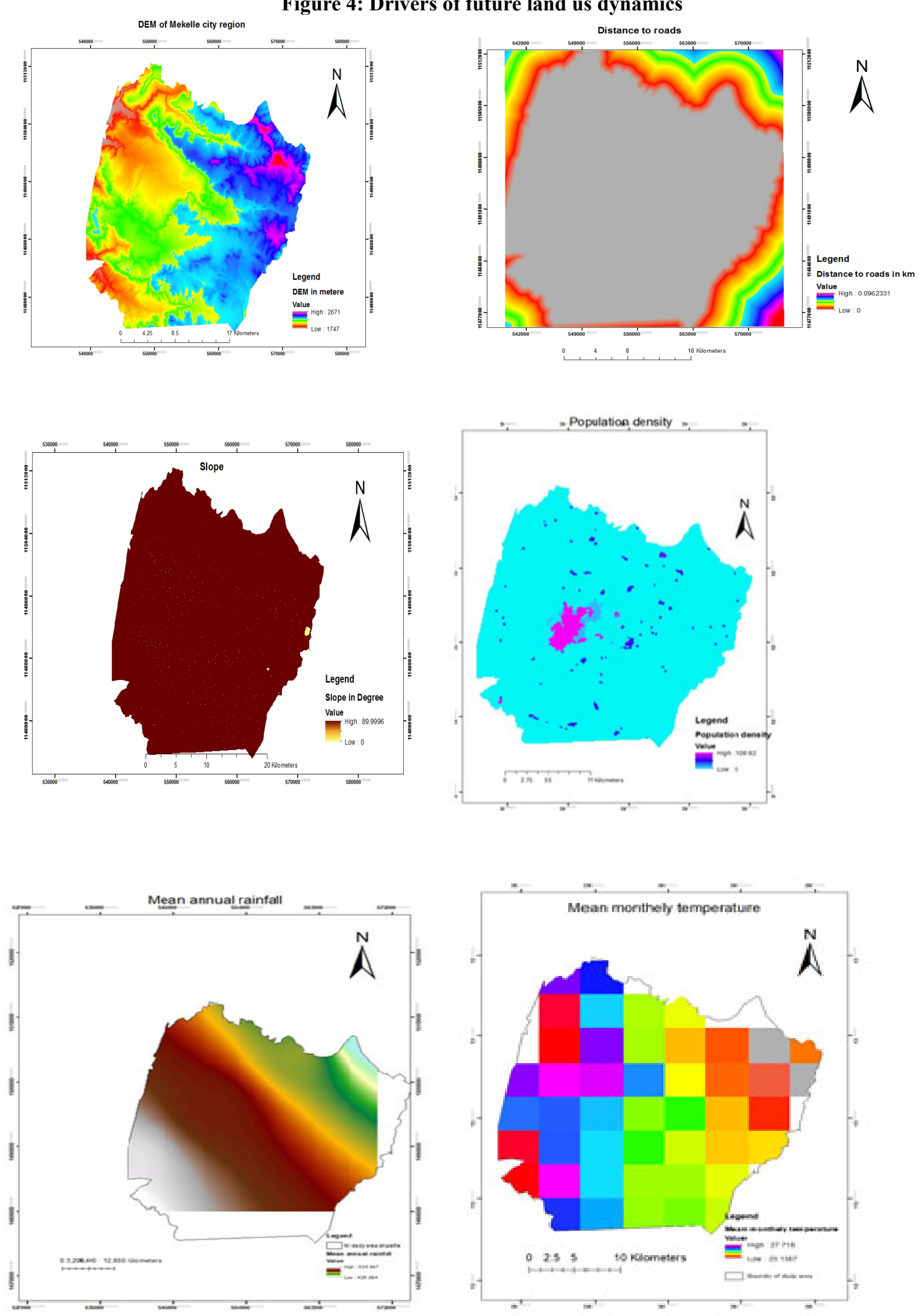

\section{Model validation and accuracy}

The presence of significant relationship between the drivers and response was assessed using the Relative operating characteristic plot (ROC)method. To assess how well the multinomial logistic regression model fits the dataset used here ROC was employed. It was used way to assess the accuracy of the model predictions by 
plotting sensitivity versus (1-specificity). The full area under a given ROC curve, formulated an important statistic that represented the probability of the prediction that will be in the correct order when a test variable was observed for one subject randomly selected drivers from the case group.

\section{Results}

\subsection{Predicted effects of land use dynamics on ecosystem services values under Different Scenarios}

The land demand under three different scenarios, land transfer rules and major driving forces, simulation of land use dynamics for the year 2030 were made. The predicted ecosystem service values of land uses/land cover under different scenarios are presented in the figures below.

Figure 5: Land-use maps of the scenario under the BAU

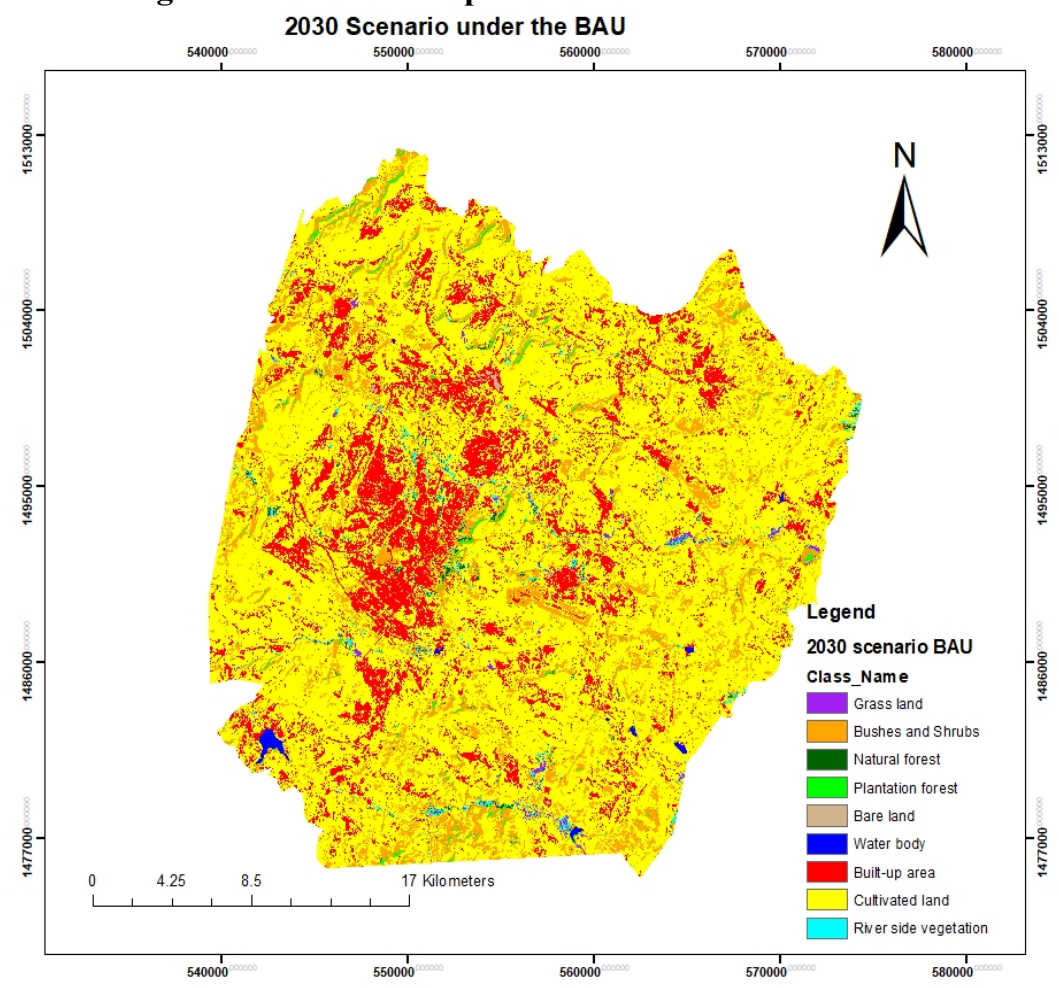

The results of scenario A (business as usual) showed that by the year 2030 it is predicted a dramatic increase in built-up areas, rising from 8897 hectares $(9.92 \%)$ in 2019 to 14692.59 hectares $(16.37 \%)$ in 2030 at the expense of natural forest, plantation forest, water bodies, cultivated land, bushes and shrubs, and riverside vegetation. The variations in land use under this scenario showed a negative impact on the ecosystem compared to the base year of 2019. This situation may be attributed to the expansion of built-up areas. 
Figure 6: Land-use maps of the scenario under PES

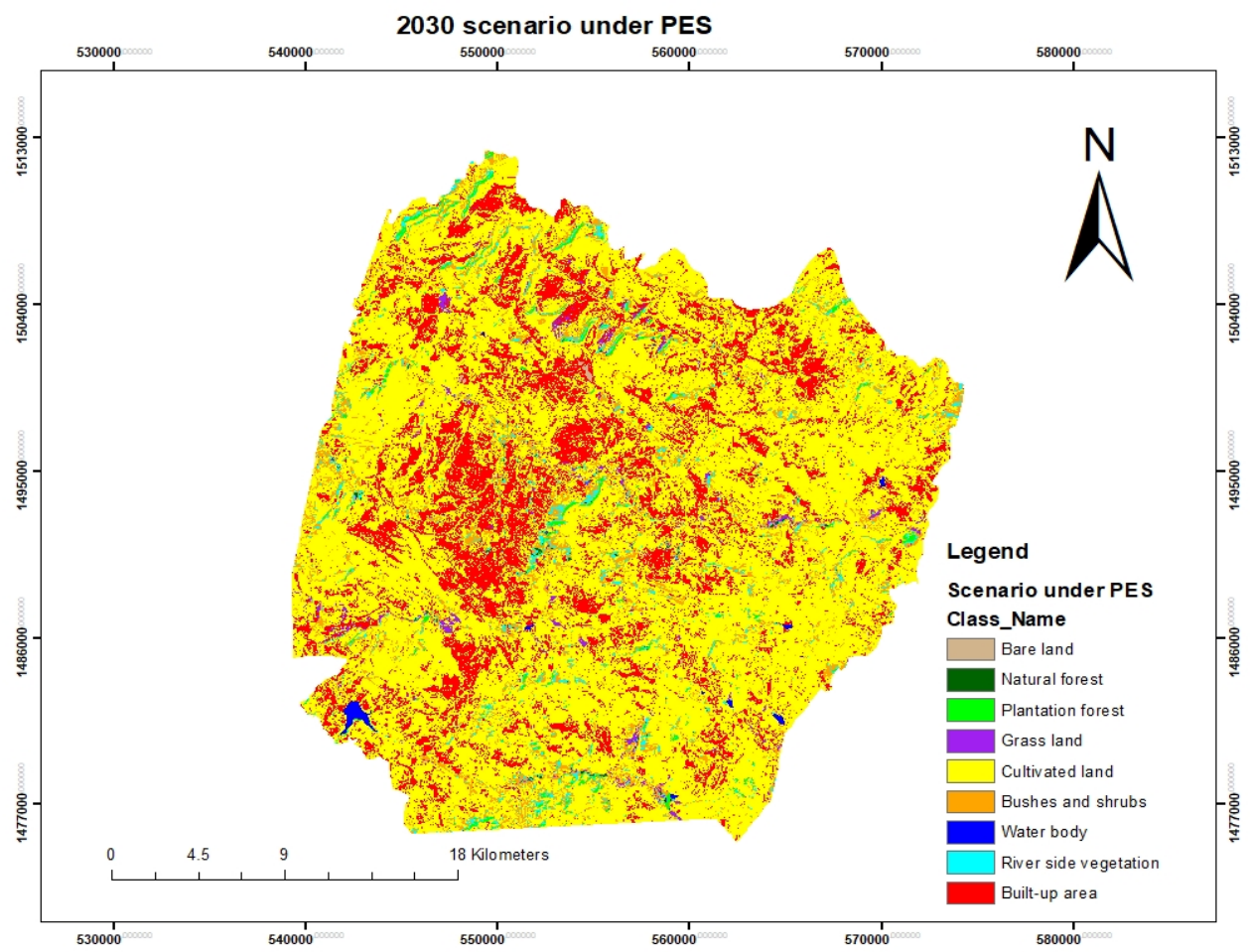

In scenario B (PES schemes), the built-up areas will continue to increases due to rapid urbanization. It will have an increase of 1439.77 hectares (9.8\%) from 2030 BAU scenario. Despite the expansion of built-up areas under scenario B, the natural forest will increase by 15 hectares $(14.86 \%)$, plantation forest by 326.52 hectares (67.14\%), water bodies by 301.62 hectares (140.93\%), grassland by $498.06(114 \%)$, riverside vegetation by 1012.32 hectares $(149.87 \%)$. However, under this scenario, cultivated land, bushes and shrubs, and bare land will be decline by 508.59 hectares $(0.82 \%), 3025.85(27.38 \%), 58.86(46.42 \%)$ respectively. The changes in land use under this scenario showed a positive impact on the ecosystem compared to the BAU scenario.

Figure 7: Land-use maps of the scenario under spatial planning scenario

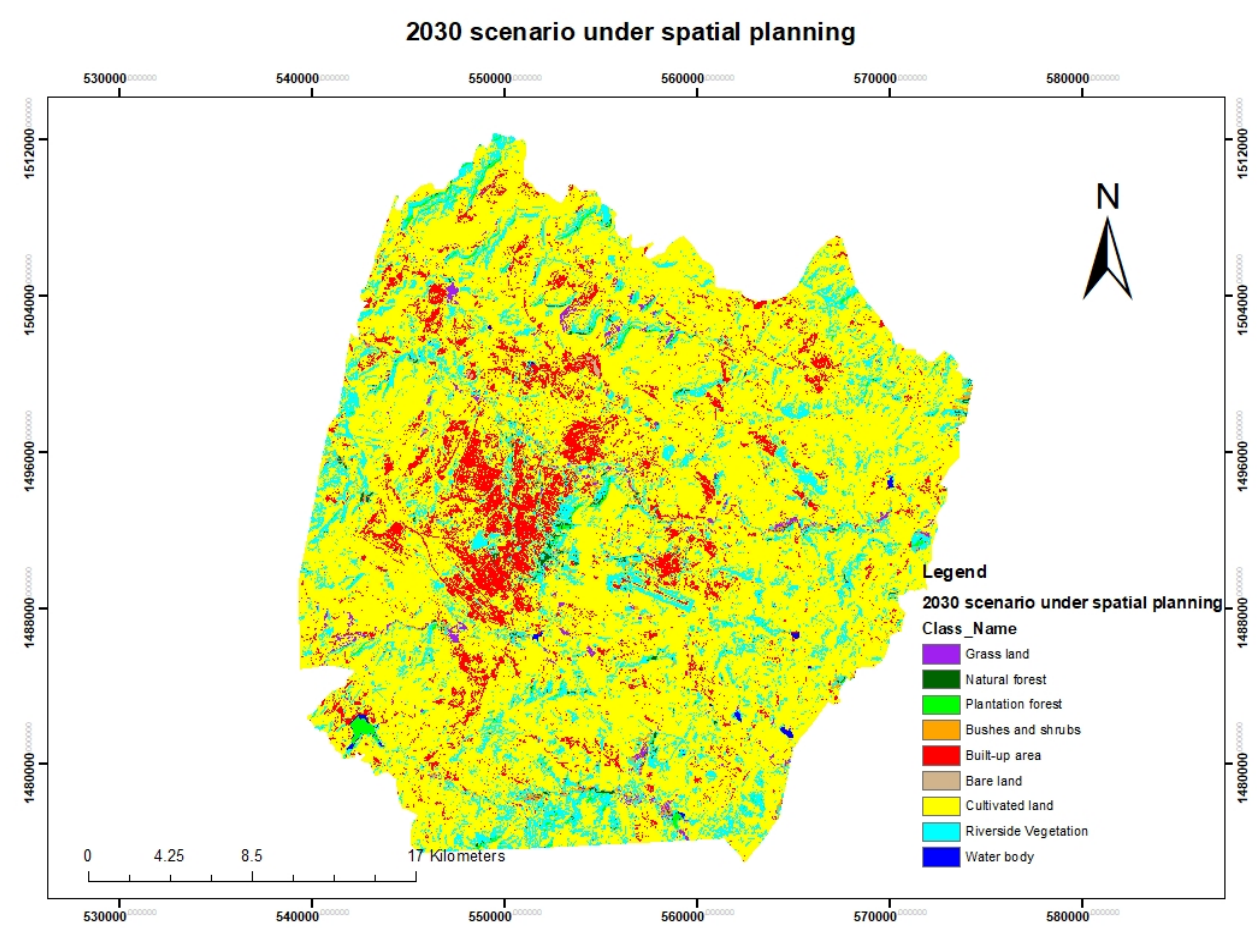


In scenario 3 (Spatial planning), the forest cover will increase considerably by 2030 . This is because, in addition to the existing ecosystem at present, the scenario aims to rise forest cover in order to increase ecosystem services values. Compared to Scenario 2 under this scenario, various LULC types such as natural forest will increase by 88 hectares $(75.86 \%)$, plantation forest by 743.86 hectares $(91.5 \%)$, water bodies by 4.05 hectare $(2.72 \%)$, and riverside vegetation by 8771.92 hectares $(519.73 \%)$. These changes in land use under this scenario showed a positive impact on the ecosystem by 2030 as compared to PES scenario. Conversely, this scenario predicts a decrease in built-up areas, cultivated land grassland, and bushes and shrubs.

3.2 Markov prediction to 2030 based on land use and land cover maps of 2019

Table 3: Land-use /land cover changes, from baseline year 2019 to 2030, under the BAU, PES, and spatial planning scenarios

\begin{tabular}{|l|l|l|l|l|l|l|l|l|}
\hline \multirow{2}{*}{ Classes } & \multicolumn{2}{l}{2019} & \multicolumn{2}{l}{ 2030 BAU } & \multicolumn{2}{l|}{$\begin{array}{l}2030 \\
\text { schemes }\end{array}$} \\
\cline { 2 - 10 } & Ha & $\%$ & Ha & $\%$ & Ha & $\%$ & Ha & $\%$ \\
\hline Built-up area & 8897 & 9.92 & 14692.59 & 16.37 & 16132.36 & 17.9 & 8099.46 & 9.12 \\
\hline Natural forest & 106 & 0.13 & 101 & 0.11 & 116.01 & 0.13 & 204.01 & 0.23 \\
\hline Plantation forest & 497 & 0.55 & 486.36 & 0.54 & 812.88 & 0.91 & 1556.74 & 1.74 \\
\hline Water bodies & 263 & 0.29 & 214.02 & 0.24 & 515.64 & 0.612 & 529.69 & 0.59 \\
\hline Cultivated land & 64843 & 72.27 & 61929 & 69 & 61420.41 & 68.5 & 60952.62 & 67.9 \\
\hline Grassland & 330 & 0.37 & 436.77 & 0.49 & 934.83 & 1.05 & 881.82 & 0.98 \\
\hline Bushes and shrubs & 13215 & 14.73 & 11050 & 12.3 & 8024.15 & 8.94 & 6951.47 & 7.75 \\
\hline Riverside vegetation & 1235 & 1.38 & 675.45 & 0.81 & 1687.77 & 1.88 & 10459.69 & 11.6 \\
\hline Bare land & 326 & 0.36 & 126.81 & 0.14 & 67.95 & 0.078 & 76.5 & 0.09 \\
\hline Total & 89712 & 100 & 89712 & 100 & 89712 & 100 & 89712 & 100 \\
\hline
\end{tabular}

From the above Markov prediction to 2030 based on land use and land cover maps of 2019 shows, the PES scenario presents the greatest built-up area expansion (17.9\%) of the total study area which is much higher than those predicted under the BAU (16.37\%) and spatial planning scenarios $9.12 \%$. The importance of spatial planning and PES schemes is clear when comparing the land-use predictions for BAU scenarios. For example, under the BAU scenario, the increase in built-up areas occurs at the expense of all other land-use types such as natural forest, plantation forest, water bodies, cultivated land, bushes and shrubs, and riverside vegetation. But under the PES scenario, the expansion of the built-up area at the expense of cultivated land, bare lands, and bushes and shrubs. The spatial planning scenario shows a decrease in built-up areas expansion and while an increase in riverside vegetation at the expense of built-up areas, cultivated land, bushes and shrubs, and grasslands. The result shows that some of the LULC classes under spatial planning scenarios will change significantly.

3.3 Estimation of future Ecosystem Service Values for the year 2030

Table 4: The ecosystem service values per hectare of different land use types for the year 2030

\begin{tabular}{|c|c|c|c|c|c|c|c|c|c|}
\hline \multirow{4}{*}{$\begin{array}{l}\mathrm{S} . \\
\mathrm{N}\end{array}$} & \multirow[t]{4}{*}{ Class name } & \multicolumn{8}{|c|}{ Area in hectares *corresponding coefficient values in millions USD } \\
\hline & & \multirow{2}{*}{\multicolumn{2}{|c|}{2019}} & \multicolumn{4}{|c|}{2030} & \multirow{2}{*}{\multicolumn{2}{|c|}{ Spatial Planning }} \\
\hline & & & & \multicolumn{2}{|c|}{ BAU } & \multicolumn{2}{|c|}{ PES Schemes } & & \\
\hline & & ESV & $\%$ & ESV & $\%$ & ESV & $\%$ & ESV & $\%$ \\
\hline 1 & Built-up area & 0 & 0 & 0 & 0 & 0 & 0 & 0 & 0 \\
\hline 2 & Natural forest & 0.105 & 0.33 & 0.100 & 0.36 & 0.114 & 0.4 & 0.2 & 0.54 \\
\hline 3 & Plantation forest & 0.490 & 1.53 & 0.479 & 1.72 & 0.800 & 2.78 & 1.5 & 4 \\
\hline 4 & Water body & 2.1 & 6.56 & 1.7 & 6.2 & 4.17 & 14.5 & 4.3 & 11.6 \\
\hline 5 & Cultivated land & 14.6 & 45.6 & 13.9 & 49.8 & 13.85 & 48.1 & 13.75 & 37 \\
\hline 6 & Grass land & 0.097 & 0.30 & 0.128 & 0.47 & 0.270 & 0.94 & 0.250 & 0.67 \\
\hline 7 & $\begin{array}{l}\text { Bushes and } \\
\text { Shrubs }\end{array}$ & 13.4 & 41.9 & 10.9 & 39 & 7.9 & 27.4 & 6.85 & 18.4 \\
\hline 8 & $\begin{array}{l}\text { River side } \\
\text { vegetation }\end{array}$ & 1.21 & 3.78 & 0.666 & 2.4 & 1.7 & 5.9 & 10.32 & 27.79 \\
\hline 9 & Bare land & 0 & 0 & 0 & 0 & 0 & 0 & 0 & 0 \\
\hline & Total & 32 & 100 & 27.98 & 100 & 28.8 & 100 & 37.2 & 100 \\
\hline
\end{tabular}

From the above table the estimation of future ecosystem service values under BAU scenario shows a decrease in total ecosystem service values from the baseline year 2019 by 4.02 million USD (12.18\%). However, PES schemes have a positive difference of $825,770.7$ USD $(+2.95 \%)$ from the BAU scenario. The prediction results for spatial planning show the increase of ESVs by 5.2 million USD (16.25\%) from the baseline year 2019. 
This study revealed that the major contributor to these future changes is a decrease in built-up area expansion and increases in riverside vegetation, natural forest, plantation forest, and water bodies.

The result in the table below revealed that there will be diverse effects of LULC variations on the various ecosystem service values; it will increase some ecosystem service values while others will probably decline. Under the business as usual scenario, there will be decline in all ecosystem service value in USD comparing with 2019 -water supply by 0.69 , food production $(0.15)$, raw material $(0.06)$, genetic resources $(0.05)$, water regulation (1.79), water treatment (0.33), erosion control(0.33), climatic regulation(0.29), biological control(0.02), gas regulation (0.02), disturbance regulation(0.01), nutrient cycling $(0.25)$,pollination $(0.02)$, soil formation (0.01), habitat (0.02), recreation(0.04) and culture(0.02).

In contrast from the BAU scenario, PES schemes is a policy intervention scenario and total ecosystem service value will be increased by $0.82 \mathrm{USD}(2.93 \%)$ ).In spatial planning scenario, compared to the baseline year 2019 the individual ecosystem service values in USD will increase water supply by 0.89 , food production(0.2), raw material(0.08), genetic resources(0.07), water regulation(2.27), water treatment(0.42), erosion control(0.0.42), climatic regulation(0.37), biological control(0.01), gas regulation (0.02), disturbance regulation(no chang), nutrientcycling(0.3), pollination(0.02), soilformation(0.02), habitat(0.03), recreation(0.03) and culture by (0.03) with an overall ecosystem service values increases of 5.2 USD(16.25\%) compared to the base year 2019.

\subsection{Estimated services of individual ecosystem functions and their predicted changes}

Table 5: Estimated value of ecosystem functions $\left(\mathrm{ESV}_{\mathrm{f}}\right.$ in US\$ million US\$ year $\left.{ }^{-1}\right)$ under each service category for the year 2019 and 2030

\begin{tabular}{|c|c|c|c|c|c|c|c|c|c|}
\hline \multirow{4}{*}{\multicolumn{2}{|c|}{ Ecosystem services }} & \multicolumn{8}{|c|}{$\begin{array}{l}\text { Annual estimated value of ecosystem functions }\left(\mathrm{ESV}_{\mathrm{f}} \text { in US\$ million }\right. \\
\left.\text { US\$ year }{ }^{-1}\right)\end{array}$} \\
\hline & & \multicolumn{8}{|c|}{$\mathrm{ESV}_{\mathrm{f2} 2030}$} \\
\hline & & \multicolumn{2}{|c|}{2019} & \multicolumn{2}{|l|}{ BAU } & \multicolumn{2}{|c|}{ PES Schemes } & \multicolumn{2}{|c|}{$\begin{array}{l}\text { Spatial } \\
\text { planning }\end{array}$} \\
\hline & & ESVs & $\%$ coverage & ESVs & $\begin{array}{l}\% \\
\text { coverage }\end{array}$ & ESVs & $\begin{array}{l}\% \\
\text { coverage }\end{array}$ & ESVs & $\begin{array}{l}\% \\
\text { coverage }\end{array}$ \\
\hline \multirow{4}{*}{$\begin{array}{l}\text { Provisioning } \\
\text { Services }\end{array}$} & Water supply & 5.5 & 17.15 & 4.81 & 17.19 & 4.95 & 17.20 & 6.39 & 17.17 \\
\hline & $\begin{array}{l}\text { Food } \\
\text { production }\end{array}$ & 1.2 & 3.74 & 1.05 & 3.75 & 1.08 & 3.75 & 1.4 & 3.76 \\
\hline & Raw material & 0.5 & 1.55 & 0.44 & 1.57 & 0.45 & 1.58 & 0.58 & 1.56 \\
\hline & $\begin{array}{l}\text { Genetic } \\
\text { resources }\end{array}$ & 0.4 & 1.24 & 0.35 & 1.25 & 0.36 & 1.25 & 0.47 & 1.26 \\
\hline \multirow[t]{7}{*}{$\begin{array}{l}\text { Regulating } \\
\text { Services }\end{array}$} & $\begin{array}{l}\text { Water } \\
\text { regulation }\end{array}$ & 14 & 43.72 & 12.21 & 43.64 & 12.57 & 43.65 & 16.27 & 43.71 \\
\hline & $\begin{array}{l}\text { Water } \\
\text { treatment }\end{array}$ & 2.6 & 8.12 & 2.27 & 8.11 & 2.34 & 8.13 & 3.02 & 8.12 \\
\hline & $\begin{array}{l}\text { Erosion } \\
\text { control }\end{array}$ & 2.6 & 8.12 & 2.27 & 8.11 & 2.34 & 8.13 & 3.02 & 8.12 \\
\hline & $\begin{array}{l}\text { Climatic } \\
\text { regulation }\end{array}$ & 2.3 & 7.18 & 2.01 & 7.18 & 2.07 & 7.19 & 2.67 & 7.18 \\
\hline & $\begin{array}{l}\text { Biological } \\
\text { control }\end{array}$ & 0.12 & 0.38 & 0.10 & 0.36 & 0.10 & 0.36 & 0.13 & 0.35 \\
\hline & Gas regulation & 0.16 & 0.5 & 0.14 & 0.5 & 0.14 & 0.49 & 0.18 & 0.48 \\
\hline & $\begin{array}{l}\text { Disturbance } \\
\text { regulation }\end{array}$ & 0.06 & 0.19 & 0.05 & 0.18 & 0.05 & 0.17 & 0.06 & 0.16 \\
\hline \multirow[t]{4}{*}{$\begin{array}{l}\text { Supporting } \\
\text { services }\end{array}$} & $\begin{array}{l}\text { Nutrient } \\
\text { cycling }\end{array}$ & 1.9 & 5.93 & 1.65 & 5.9 & 1.7 & 5.9 & 2.2 & 5.91 \\
\hline & Pollination & 0.17 & 0.53 & 0.15 & 0.54 & 0.15 & 0.52 & 0.19 & 0.51 \\
\hline & Soil formation & 0.1 & 0.31 & 0.09 & 0.32 & 0.09 & 0.3 & 0.12 & 0.32 \\
\hline & Habitat & 0.18 & 0.56 & 0.16 & 0.57 & 0.16 & 0.55 & 0.21 & 0.56 \\
\hline \multirow{3}{*}{$\begin{array}{l}\text { Cultural } \\
\text { services }\end{array}$} & Recreation & 0.22 & 0.69 & 0.18 & 0.64 & 0.19 & 0.66 & 0.25 & 0.67 \\
\hline & Cultural & 0.03 & 0.09 & 0.05 & 0.19 & 0.05 & 0.17 & 0.06 & 0.16 \\
\hline & Total & 32 & 100 & 27.98 & 100 & 28.8 & 100 & 37.2 & 100 \\
\hline
\end{tabular}

3.5 Multinomial logistic regression results

The multinominal logistic regression model was created to investigate the relationship between LULC change 
and the driving forces that play an important role in LULC change. It is used to predict the behavior of a dependent variable with respect to an independent variable. The model was run for each of the land use/land cover types and all the selected drivers of changes. The prediction analysis using the regression model identified the important drivers for each land-use class using the level of significance for each LULC class dynamics. Table 6: Correlation coefficient of independent driving forces variables

\begin{tabular}{|l|l|l|l|l|l|l|}
\hline & $\mathrm{X} 1$ & $\mathrm{X} 2$ & $\mathrm{X} 3$ & $\mathrm{X} 4$ & $\mathrm{X} 5$ & $\mathrm{X} 6$ \\
\hline $\mathrm{X} 1$ & 1 & 0.002 & 0.000 & 0.001 & 0.003 & 0.403 \\
\hline $\mathrm{X} 2$ & 0.002 & 1 & 0.005 & 0.011 & 0.000 & 0.004 \\
\hline $\mathrm{X} 3$ & 0.000 & 0.005 & 1 & 0.000 & 0.000 & 0.048 \\
\hline $\mathrm{X} 4$ & 0.001 & 0.011 & 0.000 & 1 & 0.000 & 0.033 \\
\hline $\mathrm{X} 5$ & 0.003 & 0.000 & 0.000 & 0.000 & 1 & 0.014 \\
\hline $\mathrm{X} 6$ & 0.403 & 0.004 & 0.048 & 0.033 & 0.014 & 1 \\
\hline
\end{tabular}

The regression calibration checked the existence of collinearity among independent driving forces variables and was done using a Pearson correlation coefficient in SPSS 24. As shown in the above table the collinearity is not strong.

Table 7: Multinominal Logistic regression results between LUCC and driving force

\begin{tabular}{|c|c|c|c|c|c|c|c|c|c|c|c|c|c|c|c|}
\hline \multirow[b]{2}{*}{ Driving forces } & \multicolumn{3}{|c|}{ Built-up area } & \multicolumn{3}{|c|}{ Natural forest } & \multicolumn{3}{|c|}{ Plantation forest } & \multicolumn{3}{|c|}{ Waterbody } & \multicolumn{3}{|c|}{ Cultivated land } \\
\hline & $\beta$ & S.E. & Sig. & $\beta$ & S.E. & Sig. & $\beta$ & S.E. & Sig. & $\beta$ & S.E. & Sig. & $\beta$ & S.E. & Sig. \\
\hline Pop & 0.001 & 0.000 & 0.012 & 0.350 & 0.211 & 0.062 & 0.251 & 0.313 & 0.072 & 0.191 & 0.124 & 0.123 & 0.001 & 0.000 & 0.014 \\
\hline DEM & -0.020 & 0.001 & 0.055 & 0.005 & 0.001 & 0.000 & 0.405 & 0.001 & 0.000 & 0.001 & 0.000 & 0.025 & 0.004 & 0.001 & 0.001 \\
\hline DIS & 0.001 & 0.000 & 0.100 & 0.043 & 0.017 & 0.181 & 0.032 & 0.026 & 0.261 & 0.001 & 0.000 & 0.000 & 0.000 & 0.000 & 0.033 \\
\hline SLO & 0.013 & 0.040 & 0.746 & 0.061 & 0.021 & 0.005 & 0.061 & 0.031 & 0.005 & 0.035 & 0.02 & 0.072 & 0.052 & 0.034 & 0.057 \\
\hline RAI & 0.011 & 0.009 & 0.203 & 0.033 & 0.005 & 0.154 & 0.024 & 0.005 & 0.166 & 0.003 & 0.003 & 0.158 & 0.003 & 0.006 & 0.568 \\
\hline Temp & -0.350 & 0.667 & 0.490 & 0.113 & 0.215 & 0.000 & 0.233 & 0.315 & 0.000 & 0.132 & 0.247 & 0.594 & 0.537 & 0.456 & 0.262 \\
\hline
\end{tabular}

\begin{tabular}{|c|c|c|c|c|c|c|c|c|c|c|c|c|}
\hline \multirow[b]{2}{*}{ Driving forces } & \multicolumn{3}{|c|}{ Grassland } & \multicolumn{3}{|c|}{ Bushes and shrubs } & \multicolumn{3}{|c|}{ Riverside vegetation } & \multicolumn{3}{|c|}{ Bare land } \\
\hline & $\beta$ & S.E. & Sig. & $\beta$ & S.E. & Sig. & $\beta$ & S.E. & Sig. & $\beta$ & S.E. & Sig. \\
\hline Pop & 0.186 & 0.059 & 0.001 & 0.560 & 0.329 & 0.091 & 0.450 & 0.221 & 0.072 & 0.249 & 0.143 & 0.015 \\
\hline DEM & 0.002 & 0.000 & 0.000 & 0.006 & 0.001 & 0.000 & 0.005 & 0.001 & 0.000 & 0.001 & 0.000 & 0.020 \\
\hline DIS & 0.004 & 0.013 & 0.732 & 0.024 & 0.018 & 0.192 & 0.033 & 0.017 & 0.173 & 0.005 & 0.014 & 0.687 \\
\hline SLO & 0.011 & 0.012 & 0.34 & 0.051 & 0.018 & 0.005 & 0.051 & 0.011 & 0.005 & 0.092 & 0.016 & 0.000 \\
\hline RAI & 0.003 & 0.002 & 0.184 & 0.004 & 0.004 & 0.156 & 0.013 & 0.005 & 0.245 & 0.006 & 0.002 & 0.008 \\
\hline Temp & 0.022 & 0.187 & 0.904 & 0.110 & 0.215 & 0.000 & 0.11 & 0.314 & 0.000 & 0.005 & 0.178 & 0.975 \\
\hline
\end{tabular}

From the above result, $\beta$ represents the regression coefficients between land use/land cover types and its drivers, $\operatorname{Exp}(\beta)$ represents the probability of land use/land cover type change. All driving forces are significant at $\mathrm{p}<0.05$. When $\operatorname{Exp}(\beta)>1$, this indicates the probability increases of land use types upon an increase in the value of the driving factors, and when $\operatorname{Exp}(\beta)<1$, this indicates the probability of land use/land cover type reductions.

\subsection{Calibration and validation of the model}

The ROC plot used to testify the logistic regression the one simulated for the year 2030 compared to the actual 2019 LULC map. The ROC assessed the pair of maps agree with the location of points being converted from one land use to another type of LULC. Larger values of the test result variable indicate stronger evidence for a positive actual state. The test result variable shows Population density has at least one tie between the positive actual state group and the negative actual state group. The positive actual state is the Built-up area. An ideal model would have an area of 1.000 , and this logistic model has the largest area under the curve of 0.73 with a standard error of 0.38 in the figure below. The test result variables namely yearly average temperature, mean annual rainfall, population density, DEM, Slope has at least one tie between the positive actual state group and the negative actual state group. Statistics may be biased. 
Figure 8: ROC curve

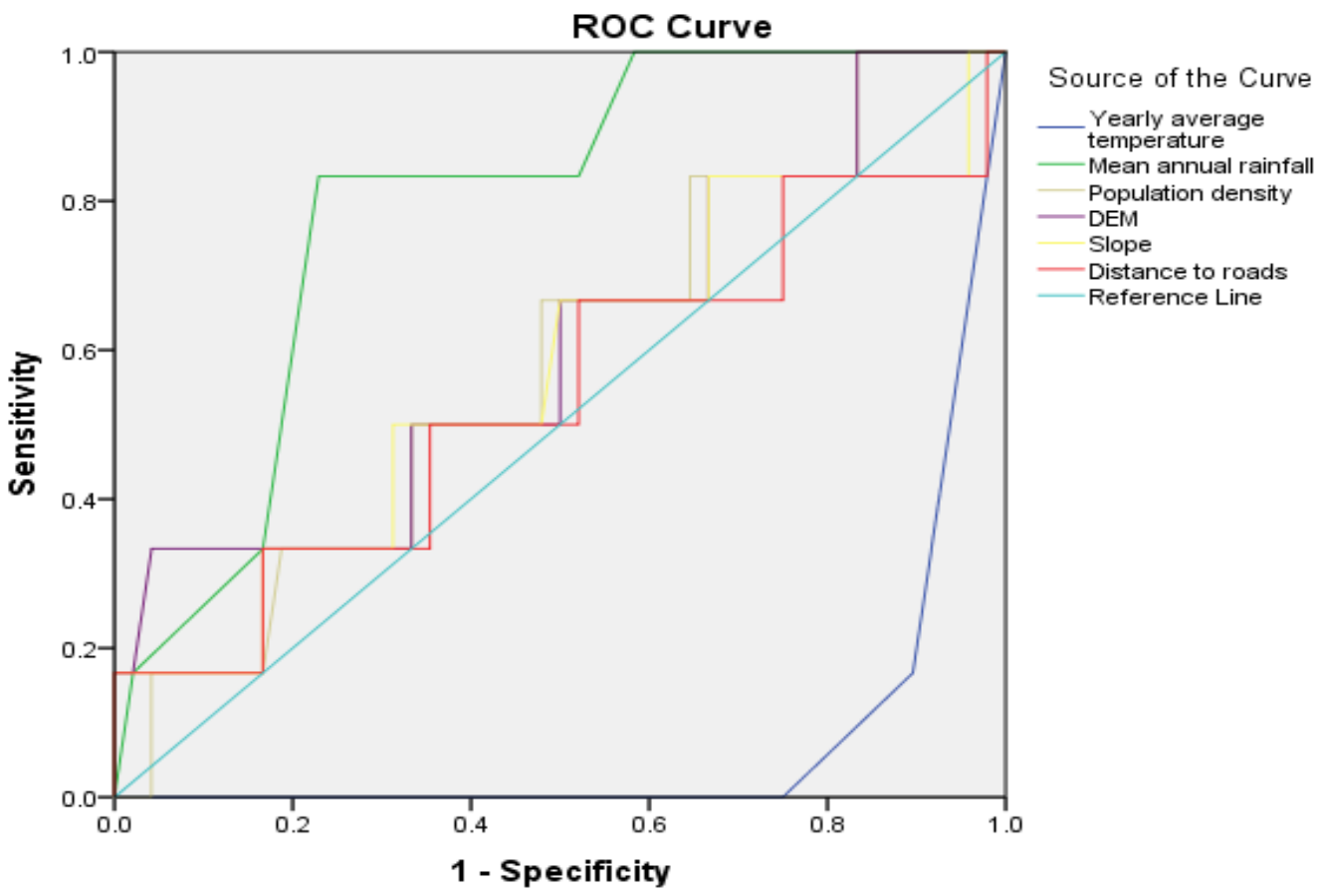

Diagonal segments are produced by ties.

The area under the ROC curve is used to measure the overall model performance. It was interpreted as the average value of sensitivity for all possible values of specificity 1 . The closer AUC is to 1, the better the overall analytical performance of the test, and a test with an AUC value of 1 is one that is perfectly accurate. The practical lower limit for the AUC of a diagnostic test is 0.5 . The line segment from 0,0 to 1,1 has an area of 0.5(Park, Goo, \& Jo, 2004). The classifiers that gave curves closer to the top-left corner in the above indicate better performance. The above model interpretation indicates the ROC curve (the green line) in the top left corner of the plot, which indicates that the model does a good job of predicting mean annual rainfall will have a significant impact on future LULC.

Table 8: Area Under the Curve (AUC)

\begin{tabular}{|l|r|}
\hline Test Result Variable(s) & Area \\
\hline Yearly average temperature & 0.073 \\
\hline Mean annual rainfall & 0.792 \\
\hline Population density & 0.582 \\
\hline DEM & 0.606 \\
\hline Slope & 0.568 \\
\hline Distance to roads & 0.538 \\
\hline
\end{tabular}

The ROC test of five driving forces of LULC changes is greater than 0.538 except yearly average temperature which shows clearly that the spatial distribution for all land use categories can be explained by the related driving factors. Under the three scenarios, future urbanization will be concentrated in the core city of the study area in Mekelle city, where the urbanization will continue. However, the use of different LULC scenarios decreases the uncertainties associated with the model and enhances the applicability of simulation results. To reduce uncertainty logistic regression was also used. The accuracy of the model was tested by comparing the 2019 LULC map with its simulated complement. Generally, the validation shows a satisfactory result, which shows that the simulation model can be used to simulate future LULC.

\subsection{The nexus between simulation of land use dynamics and ecosystem services valuation with sustainability development goals}

To ensure the sustainability of Mekelle city region considering the three pillars of sustainability is crucial. The economic, environmental, and social pillars are vital in understanding sustainability. If any one of the three pillars is fail then the ecosystem services provision as a whole can become unsustainable. This study considered the economic, ecological, and social values in valuing ecosystem services. The results of ecosystem service valuation in Mekelle city region show an unsustainable path, and there is a need to get on a sustainable one. In 
this study the goal of the ecosystem service valuation is to contribute to a more sustainable and equitable natural resource use. The final goal of ecosystem services valuation is to improve the well-being of every individual living now in the study area, currently, and in the future. This study followed the strong sustainability view i.e the economy is merely a sub-system of society, which is itself a sub-system of the environment, all being interdependent.

During valuation, this study respected the principles of sustainable development. The development in Mekelle city region should meet the needs of current residents without compromising the ability of future generations to meet their own needs. Economic and social well-being cannot be improved with measures that destroy the environment.

The ecological valuation and ecosystem assessment was the first step during ES valuation. The social and monetary values depend on the ES production. The production functions described here how ecosystems generate services were acknowledged. The economic valuation of ES is considered for value in a broader sense including the social and ecological qualities embedded in these services, which are perceived by those who benefit from ES at different scales. The social valuation of ES involves the collective decisions through deliberation allow actors to decide who gives up what as part of a negotiation and collective learning process. The value formation occurred through expert discussion. The valuation process was transparent in order to be used for decision-making. When valuing ES, the questions of governance cannot be ignored. Valuation exercises always take place in a given institutional setting. Because ecosystem services are common goods, this institutional setting ideally favors social rationality and communicative action, warranting that a societal perspective was considered.

In social-ecological systems theory social refers to the human dimension, including economic, political, technological, cultural, and ecological, and are embedded parts of the biosphere and shape it. Societies will continue to be shaped by the biosphere and there is a growing recognition of the need for development approaches that take account of the interdependencies between human well-being and the biosphere e.g., SDGs goals. The results of the study are in line with sustainable development goals 11 and 15 .

Goal 11: Make cities and human settlements inclusive, safe, resilient, and sustainable and 11.a support positive economic, social and environmental links between urban, peri-urban, and rural areas by strengthening national and regional development planning. The concept of city region considers both urban and rural areas it is with the goals of this sustainable development goal. Besides, goal 15: Protect, restore and promote sustainable use of terrestrial ecosystems, sustainably manage forests, combat desertification, and halt and reverse land degradation and halt biodiversity loss

15.9 By 2020, Integrate ecosystem and biodiversity values into national and local planning, development processes, poverty reduction strategies, and accounts. This study applied ecosystem services valuation to understand the environmental degradation and sustaining ecosystem services provision. Based on WCED of 1987 report, this study applied the three pillars of sustainability namely economy, society, and environment.

\subsection{Discussion}

CLUMondo model was used to predict the land use dynamics until 2030 and the year for sustainable development goals achievement target was selected. In order to guide future development in Mekelle city and its hinterlands prediction of LULC and its effects on ecosystem service values is vital. In the study area, there is an economic boom in and this could have short-term and long-term effects on ecosystem service values. When major changes in ecosystems and ecosystem services are at stake with the expected change in, as a consequence of land-use change or economic/environmental policy, structured and transparent valuations are appropriate, in the proper temporal and spatial contexts(Robert Costanza \& Steve Farber f, 2017).

This study weighs the approaches and different software packages for modeling LUCC such as CLUMondo, GeoSOS, LanduseSim, LuccME, SAGA GIS, SLEUTH GA, QGIS MOLUSCE,Dinamica Ego, UrbanCA,future land use simulation model(FLUS), and IDRISI Selva 17.02. This study reviews the possibilities and the limits of these modeling software packages. First, a revision of the methods and tools available for each model was performed, taking into account how the models carry out the different procedures involved in the modeling process: quantity of change estimate, change potential evaluation, spatial allocation of change, reproduction of temporal and spatial patterns, model evaluation and advanced modeling options. Additional considerations, such as flexibility, user-friendliness, were also taken into account. Then, the models were applied to the study to illustrate the previous descriptions with a typical LUCC scenario that consists of processes of change. The outputs were compared to assess the change estimates, the change potential, and the simulated maps. However, due to its compatibility the study utilized CLUDMondo version 1.4.0. The simulation tool was tested in simulating future land-use changes and ecosystem services in northern Thailand by(Arunyawat \& Shrestha, 2018).

In order to understand the change in ecosystem service value resulting from a change in land-use and land cover, this study begins with a scenario that exhibits different types of land-use change. The scenario generator 
creates different patterns of conversion according to the LULC inputs. The CLUMondo creates maps of land-use change according to user-assigned probabilities that certain transitions will occur. The changes in land use/land cover were made in response to demands for various goods and services provided by the land, such as cultivated land converted for providing built-up areas. Changes in these demands can result in land use/land cover conversion, an increase in cultivated land demand led to conversion from forests to cultivated land and a growing population led to an increase in built-up area. The future land-use scenarios for the year 2030 were simulated as business-as-usual, application of possible PES schemes, and spatial planning. Under BAU scenario if the existing condition is not improved in terms of land use planning and introducing new policies such as PES schemes ecosystem service values will probably drop sharply.

Different studies employed different driving criteria to study LULC scenario modeling. For example, predicting urban growth using a statistical modeling approach by (Manu, Twumasi, Lu, \& Coleman, 2015) and Integration of logistic regression, Markov chain and cellular automata models to simulate urban expansion(Arsanjani, Helbich, Kainz, \& Boloorani, 2013). But this study is unique in selection of drivers. This study applied LULC modeling including the statistical, spatial, and driver-based method with quantitative future land use prediction.

Previous studies used different modeling tools and logistic regression for predictive land-use modeling. This study will be amongst the first to simulate future LULC changes under different scenarios at the city-region level. The developed scenarios in Mekelle city region are different from the existing ones. logistic regression is one of the most common approaches used in land use allocation models to determine the relationship between land use dynamics and its driving forces. However, these models have a drawback in that they do not determine/allocate land use based on the direct multi-class problem of land-use change and its driving factors. The model has a weakness in that it does not determine land use based on the direct relationship between landuse change and its driving factors. Accordingly, a multinomial logistic regression method was introduced to the study to address this defect. The application of this method in future land-use change studies may improve the accuracy of predicting the effects of land use and cover change on ESVs.

This study showed that spatial analysis and multinomial logistic regression produced a meaningful model of drivers of LULC changes. The population of Mekelle city region will grow over 1.4 million inhabitants by 2030, and the land demands will exceed the sustainable capacity of land use. Spatial planning has got little attention in the study area. Continuous urbanization and population growth and the impact of climate changes will place additional stress on the ecosystem unless appropriate integrated planning and management actions are put in place. Urban planners need scenario estimation tools to achieve sustainable development.

\section{Conclusion and recommendation}

The aim of the study was to predict plausible future land use scenarios through mapping and quantification of ESVs.This study explored how future land-use changes would affect ecosystem service values, under three different scenarios for the year 2030. The land use scenario in 2030 is predicted, and the value of ecosystem services is estimated. CLUDMondo model has been used to predict future land use and land cover maps of year 2030 based on the data. Based on logistic regression analysis, the contribution of driving forces to the land use and cover change was obtained. To validate land-use dynamics simulation ROC method was used for model's prediction accuracy.

This study indicated the reductions in the total and individual ecosystem service values in response to LULC changes under BAU scenario. The results show that the value of ecosystem services will continue to decreases. It was found that the significant expansion of built-up area and lessening of various ecosystem services are expected in 2030 that negatively affects their values. Under the PES and spatial planning scenarios show the largest increase in ESVs. The PES is relatively better compared with the BAU scenarios, due to new policy implementation on ecological land. As a result, the spatial planning scenario show the highest amount of ESVs. Based on these findings, it is proposed new land-use strategies, to achieve sustainable use of ecosystem services in the study area. This study can guide future land-use planning and raise public awareness of the need for ecosystem protection. The identification of trends in land cover change and ecosystem service defined in this study could help develop future scenarios to tackle future challenges in ecosystem service supply. Overall, these results provide useful inputs to the LULC planners and resources managers to adopt eco-friendly policies and regulations and for encouraging sustainable development goals.

In this regard, it is suggested (1) a comprehensive understanding of future land use dynamics scenarios and their environmental impacts is needed by spatial planners to make sound decisions in practicing sustainable land management (2)governmental agencies should use could scenario simulation to determine how to manage lands, to provide a desirable range of benefits to people, or to help design permitting and mitigation programs that sustain nature's benefits to society(3) efficient land use systems through regional spatial planning need to be implemented and (4)there is the need for policy changes, and the findings of the study can contribute towards achieving SDGs. The study finding can also serve as the starting point in developing sustainable land uses for 
environmental conservation in Ethiopias's major urban centers. The results provide a quantitative systematic report that policymakers and land managers can use to identify and prioritize the best practices to sustain ecosystem services.

\section{Acknowledgments}

My thanks go to Tigray Bureau of trade, industry and urban development, Tigray (Ethiopia), bureau of civil service and Ethiopian civil service university for giving me the opportunity to pursue this study and for the financial support, without which this achievement would not have been possible. I would like to thank all institutions and individuals at national, regional, district and city levels who provided us information for this study.

\section{Declaration of interest}

The authors declare that they have no competing interests.

\section{Ethics approval}

Not applicable.

\section{Consent to participate}

The author needs to accept and confirm the manuscript have read and agreed to its content and are accountable for all aspects of the accuracy and integrity of the manuscript. The article is original, has not already been published in a journal, and is not currently under consideration by another journal.

\section{Consent for publication}

The author is volunteer for publication of original research findings entitled "Scenario Simulation of ecosystem services value changes and its implication for sustainability development goals ". The author grants Journal of Resources Development and Management a license to publish the article and identify itself as the original publisher.

\section{Availability of data and material}

The dataset(s) supporting the conclusions of this article is (are) available in the Google scholar, JSTOR, Google that all publicly available datasets are fully referenced in the reference list.

\section{Authors' contributions}

1) The Author (shishay kiros) makes substantial contributions to conception and design, and/or acquisition of data, and/or analysis and interpretation of data;

2) The Co-author (kumelachew yeshitela) contribution is on conceptual design, Interpretation of data and write up;

3) Ranavijai Singh revising critically for important intellectual content and edited the manuscript.

\section{Authors' information}

1.Kumelachew Yeshitela (Ph.D.) is an associate professor of Urban Ecology at Ethiopian Institute of Architecture, Building Construction and City Development, Addis Ababa University, Addis Ababa, Ethiopia. He is Chair of Ecosystem Planning and Management. He has published 47 scientific works in international reputable journals.

2.Ranavijai Singh, Ph.D, Associate Professor, College of Urban Development and Engineering, Ethiopian Civil Service University, Ababa, Ethiopia.

3. Shishay is a Ph.D. Candidate in Environmental sustainability and Climate change resilience at Ethiopian Civil Service University, Addis Ababa.

\section{References}

Abreha, A. G. (2014). Hydrogeochemical and Water Quality Investigation on Irrigation and Drinking Water Supplies in the Mekelle Region, Northern Ethiopia (MSC), University of Twente 2014.

Ardavan Zarandiana, H. B., Nigel E. Storkc, Matthew A. Lingd,Ahmad R. Yavarie, Hamid R. Jafarif, Hamid Amirnejad. (2017). Modeling ecosystem services informs spatial planning in lands adjacent to the Sarvelat and Javaherdasht protected area in northern Iran. Land use policy, 487-500.

Arsanjani, J. J., Helbich, M., Kainz, W., \& Boloorani, A. D. (2013). Integration of logistic regression, Markov chain and cellular automata models to simulate urban expansion. International Journal of Applied Earth Observation and Geoinformation, 21, 265-275.

Arunyawat, S., \& Shrestha, R. P. (2018). Simulating future land use and ecosystem services , Northern Thailand. 
Journal of Land Use Science, 13(1-2), 146-165.

Costanza, R., d'Arge, R., De Groot, R., Farber, S., Grasso, M., Hannon, B., . . Paruelo, J. (1997). The value of the world ecosystem services and natural capital. nature, 387(6630), 253.

Fu, Q., Hou, Y., Wang, B., Bi, X., Li, B., \& Zhang, X. (2018). Scenario analysis of ecosystem service changes and interactions in a mountain-oasis-desert system: a case study in Altay Prefecture, China. Scientific reports, $8(1), 1-13$.

Houet, T., Verburg, P. H., \& Loveland, T. R. (2010). Monitoring and modelling landscape dynamics. Landscape ecology, 25(2), 163-167.

Hu, S., Chen, L., Li, L., Zhang, T., Yuan, L., Cheng, L., . . Wen, M. (2020). Simulation of land use change and ecosystem service value dynamics under ecological constraints in Anhui Province, China. International journal of environmental research and public health, 17(12), 4228.

Kindu, M., Schneider, T., Teketay, D., \& Knoke, T. (2015). Drivers of land use/land cover changes in MunessaShashemene landscape of the south-central highlands of Ethiopia. Environmental monitoring and assessment, 187(7), 452.

Li, J., Chen, H., Zhang, C., \& Pan, T. (2019). Variations in ecosystem service value in response to land use/land cover changes in Central Asia over 1995-2035: PeerJ Preprints.

Li, Z., Cheng, X., \& Han, H. (2020). Future Impacts of Land Use Change on Ecosystem Services under Different Scenarios in the Ecological Conservation Area, Beijing, China. Forests, 11(5), 584.

Manu, A., Twumasi, Y. A., Lu, K. S., \& Coleman, T. L. (2015). Predicting urban growth of a developing country city using a statistical modeling approach. International Journal Of Geomatics And Geosciences, $5(4), 603-613$.

Olosutean, H. (2015). Methods for modeling ecosystem services: a review. Management of Sustainable Development, 7(1), 5-12.

Pandeya, B., Buytaert, W., Zulkafli, Z., Karpouzoglou, T., Mao, F., \& Hannah, D. (2016). A comparative analysis of ecosystem services valuation approaches for application at the local scale and in data scarce regions. Ecosystem Services, 22, 250-259.

Park, S. H., Goo, J. M., \& Jo, C.-H. (2004). Receiver operating characteristic (ROC) curve: practical review for radiologists. Korean journal of radiology, 5(1), 11.

Robert Costanza, R. d. G., Leon Braat, Ida Kubiszewski, Lorenzo Fioramonti, Paul Sutton , \& Steve Farber f, M. G. g. (2017). The Twenty years of ecosystem services: How far have we come and how far do we still need to go? Elsevier.

Tatem, A. (2015). Demographics of Ethiopia. from World bank group

TCSA. (2019). Tigray population data Demography. Tigray stastical agency.

Tolessa, T., Gessese, H., Tolera, M., \& Kidane, M. (2018). Changes in ecosystem service values in response to changes in landscape composition in the central highlands of Ethiopia. Environmental Processes, 5(3), 483501.

Van Vliet, J., \& Verburg, P. (2018). A short presentation of CLUMondo Geomatic approaches for modeling land change scenarios (pp. 485-492): Springer.

Veen, T. G. a. A. v. d. (2014). The Effect of Enclosures in Rehabilitating Degraded Vegetation: A Case of Enderta District, Northern Ethiopia Forest Research.

Verburg, P., Vliet, J., Malek, Z., \& Ornetsmuller, C. (2015). The CLUMondo land use change model: Manual and exercises. Institute for Environmental Studies, University Amsterdam.

Yang, H. (2008). An ecosystem service value assessment of land-use change on Poyang Lake Basin under 3S technology, China. The International Archives of the Photogrammetry, Remote Sensing, and Spatial Information Sciences, 37.

Yirsaw, E., Wu, W., Shi, X., Temesgen, H., \& Bekele, B. (2017). Land use/land cover change modeling and the prediction of subsequent changes in ecosystem service values in a coastal area of China, the Su-Xi-Chang Region. Sustainability, 9(7), 1204.

$\underline{\text { N.B }}$ The above references were properly cited and referenced using End Note reference manager version 7.1. 